\title{
OPTIMIZATION AND COMPARATIVE STUDY OF THE TURNING PARAMETERS OF DCT TOOL IN THE MACHINING OF COMMERCIAL STEEL
}

\section{S.V. SATYA PRASAD, P. PRASANNA KUMARI, A.V. PRADEEP, K. VAHINI \& P. KIRANMAYI}

Mechanical Engineering, Vignan's Institute of Engineering for Women, Andhra Pradesh, India Mechanical Engineering, Vignan's Institute of Engineering for Women, Andhra Pradesh, India Mechanical Engineering, Vignan's Institute of Engineering for Women, Andhra Pradesh, India

Mechanical Engineering, Gayatri Vidya Parishad School of Engineering, Andhra Pradesh, India

\begin{abstract}
Turning is a machining process where steel tools are the materials generally used in tool bits. There fore tool material properties have a major impact on the turning operation. Enhancement of tool steel properties will improve machining. Present work deals with the process of deep cryogenic treatment (DCT) done on a high speed steel tool bit with a single cutting edge. This enhances the machining of different work piece materials having good surface finish with increased tool life. The turning has carried out at a constant depth of cut $(D C)$ and feed rate $(F)$ on a commercial tool having material of SS304 using both cryogenic treatment(CT) and also non-treated high-speed tool steel bit sat at three variable speeds with an interval of 03 minutes up to the tool bit nose fracture is achieved. From the results, graphs were drawn for wear and the time at each speed, and evaluate those results with tool life finally it is observed that the CT has resisted more time when compared to a tool with non cryogenically treated(NCT) at a given speed with increasing tool life. Using the cryogenically treated $(C T)$ tool, the turning parameters of feed $(F)$, speed $(S)$ and depth of cut $(D C)$ at three levels were considered and using the design of experimentation, $L 9$ orthogonal tool array was taken to find the optimized parameters in the turning of SS304. The response of the cutting parameters on flank wear (FW) and surface roughness(SR) was done using ANOVA in MINITAB and the interaction plots were plotted.
\end{abstract}

KEYWORDS: Cryogenic Treatment, Tool Nose Fracture, Tool Life, Surface Roughness, Flank Wear

Received: Jun 09, 2020; Accepted: Jun 29, 2020; Published: Jul 18, 2020; Paper Id.: IJMPERDJUN2020379

\section{INTRODUCTION}

In turning, the cutting tool moves against the rotating work piece. The tool parallelly moves along the length of the work piece removing excess material as chips. During the metal removal process, high heat is liberated due to friction between the tool chip interfaces. This leads to wear a tool and finally the tool gets failed. Based on this wide research has done on cryogenics. Cryogenics is the study about very low temperature, and also we will observe different properties of the materials at lower temperatures. The work related to cryogenic treatment dates long back where F.F Barron (1982) [22], has conducted several tests on HSS tools. From his results, he concluded that the CT process increases wear resistance, thermal stability and surface hardness of the materials. Molinari et. Al. (2001)[14] observed that deep cryogenic treatment process improves more mechanical properties in the quenching and tempering process. Benfred et. Ai (2006)[7] observed the images taken from scanning electron microscopy(SEM), the material is removed by shearing and ploughing instead of sliding action on its surfaces due to cryogenic temperatures. F. Cajner et al. (2008)[10], worked on the effect of DCT on high speed steels and stated in their report that the high speed steels are best suited for 
cryogenic treatment and exhibit excellent enhancement in their material properties. T.V. Sreerama Reddy et al. (2009) [28], concluded in their experiments that cutting forces to be reduced due to the cryogenic treatment in HSS tool. This is because of less significant distortion and wears being observed near the edge of the cryogenically treated tool which interacts with the work piece. Lakh winder Pal Singh et al. (2011) [13], also worked on high speed steels and the effect of cryogenic treatment on it. They observed lower weight loss, less reduction in nose radius, uniform distribution of metal particles, and a refined microstructure of Cryogenically Treated HSS tool and also work piece surface roughness [11] value is lowered after machining. The power consumption is also reduced in the cryogenically treated tool. A.D. Shirbhate et al. (2012)[1], in their reports have suggested that among all the cutting tools, the turning operation carried out by a single edge cutting tool has the maximum tool life in case of CT. The concept of ANOVA was used to optimize the turning parameters. D. Candane et al. (2013)[8], studied various microstructures of materials and their mechanical properties using cryogenically treated tools. he observed that due to CT the conversion of microstructure from austenite state to marten site state the materials has more hardness and touthness, uniform distribution of carbides within the materials, and also we observed that the left over austenite is completely transformed at lower temperatures in steels[15]. Sunil Magadum et al. (2014) [6], had kept the constant F and DC is carried out on cryogenic machining Ahmed M et al. (2007)[2] concluded that there is an improvement in tool life by $61 \%$ in case of cryogenic machining over conventional machining. In the present experimental work, the effect of DCT on HSS tool and a comparison has been done on between CT and NCT HSS tools, and the tool life was found out by carrying out the machining till nose fracture. Also, the response of cutting parameters of S, F and DC has been seen on flank wear and surface roughness by analysis using ANOVA.

\subsection{Selection of Material for Work Piece and a Tool}

\subsubsection{Selection of Material for Work Piece}

Stainless steel SS304 material [26], which is the commercial grade work piece, has been selected for experimentation. The composition of material for the work piece is in Table 1.

Table 1: Work Piece Composition

\begin{tabular}{|c|c|c|c|c|c|c|c|}
\hline Metals & $\mathbf{C}$ & $\mathbf{S i}$ & $\mathbf{P}$ & $\mathbf{M n}$ & $\mathbf{S}$ & $\mathbf{N i}$ & $\mathbf{C r}$ \\
\hline \% of composition & 0.08 & 0.76 & 0.045 & 2 & 0.02 & 8.01 & 18 \\
\hline
\end{tabular}

\subsubsection{Selection of Tool}

High Speed Steel [3] tool has been selected for experimentation.M2 grade material of S400 was procured of Miranda company (ISO 9002). The high speed steel tool blanks were grinded as per the desired tool angles. Before the grinding process we sent the tools for the DCT to Cryoking, in Surat. The table 2 shows \%of chemicals in the the tool.

Table 2: Chemical \% in Tool

\begin{tabular}{|c|c|c|c|c|c|}
\hline Metals & C & W & V & Mo & Cr \\
\hline$\%$ of composition & 0.94 & 6 & 2 & 5 & 4 \\
\hline
\end{tabular}

\subsection{Experimentation Work}

\subsubsection{Deep Cryogenic Treatment (DCT)}

The DCT process was conducted in the following procedure, the parameters are given in the following table. 3 
Table 3: Cryogenic Treatment Process Parameters

\begin{tabular}{|l|c|}
\hline Soaking temperature & $-195^{\circ} \mathrm{C}$ \\
\hline Soaking period & $24 \mathrm{hours}$ \\
\hline Rate of Cooling & $1{ }^{\circ} \mathrm{C}$ per min \\
\hline Heating rate & $1^{\circ} \mathrm{C}$ per min \\
\hline Tempering temperature & $200^{\circ} \mathrm{C}$ \\
\hline Total cycle time & $34 \mathrm{hrs}$. \\
\hline Tempering cycle & 1 \\
\hline Tempering period & $1 \mathrm{hr}$. \\
\hline
\end{tabular}

\subsubsection{Experimental Procedure}

The experimental procedure was carried out in two different parts; the first part of the procedure was to compare the CT [4] and NCT high speed steel single point cutting tools. For this purpose the F and DC were set constant and time duration of 15 minutes was fixed to find out the surface roughness and tool flank wear. At regular time intervals of 3 minutes the influencing factors like cutting forces, flank wear and surface roughness were observed and tabulated for both cryogenically treated and non-treated tools. Later on, to find out the tool life, the flank wear was observed until a fracture was seen on the nose of the HSS tool.

The different speeds i.e., low medium and high speeds are taken for machining different lengths by maintaining the F: $0.05 \mathrm{~mm} / \mathrm{min}$ and DC: $0.5 \mathrm{~mm}$ as constant parameters. The initial Diameter of the rod is $25 \mathrm{~mm}$. Table 4 below shows the speeds and lengths of the raw material considered for the experimentation.

A table 4 show the second part of the experimentation was work is to consider the influence of cutting variables on the wear of tool, surface roughness, and their relation. For these process parameters like cutting velocity, F and DC were selected. Table 5 below shows the preferred process parameters for machining the commercial grade stainless steel (SS304) work piece. A cryogenically treated S400 HSS single cutting edge tool was used. Turning operations were done on a lathe and using tool maker's microscope flank wear was measured frequently. The surface roughness values were taken from a talysurf. The length of the work piece was taken constantly at $120 \mathrm{~mm}$ and the diameter of the work piece is $25 \mathrm{~mm}$ for this experimentation. Major factors affecting on tool wear and surface roughness were found by using the Design of experiments (DOE).

Table 5 shows now for the CT tool, various cutting parameters are considered as S, F and DC and for each of these cutting parameters we have three levels. Thus the factorial design is in the form $\mathrm{P}^{\mathrm{n}}$ can be written as $3^{3}$. This will give us 27 iterations. This can be optimized in the MINITAB using the design of experiments and an orthogonal array of L9 can be obtained. This L9 orthogonal array has been used for experimenting. This reduces our iterations to 9 and simplifies the process of experimentation.

Table 4: Dimensions of the Raw Material

\begin{tabular}{|l|c|c|}
\hline Type of Speed & Speeds Taken(Rpm) & Work Piece Length(Mm) \\
\hline Low speeds & 180 & 127 \\
\hline Medium speeds & 300 & 145 \\
\hline High speeds & 540 & 179.5 \\
\hline
\end{tabular}

Table 5: Cutting Parameters of Different Levels

\begin{tabular}{|c|c|c|c|}
\hline \multicolumn{3}{|c|}{ Cutting Parameters } & Levels \\
\hline Speed (Rpm) & Feed (Mm / Rev) & Depth of Cut(Mm) & \\
\hline 180 & 0.05 & 0.1 & 1 \\
\hline 300 & 0.1 & 0.2 & 2 \\
\hline 540 & 0.15 & 0.3 & 3 \\
\hline
\end{tabular}




\section{RESULTS AND DISCUSSIONS}

\subsection{Comparison between Cryogenically Treated and Non-Treated Tools}

The main objective is to find out the performance of the CT HSS tool in comparison to the non-treated HSS tool. After the experiment, the following observations were recorded for both CT and NCT tools as shown in tables 6 and 7 below.

Table 6: Cryogenically Treated Tool Bit Experimental Values

\begin{tabular}{|c|c|c|c|c|c|c|c|}
\hline \multirow{2}{*}{ S. No } & \multirow{2}{*}{$\begin{array}{l}\text { Speed } \\
(\mathbf{R p m})\end{array}$} & \multirow{2}{*}{$\begin{array}{l}\text { Time } \\
\text { (Min) }\end{array}$} & \multicolumn{3}{|c|}{ Cutting Forces (Kgf) } & \multirow{2}{*}{$\begin{array}{c}\text { Surface Roughness } \\
\mathbf{R}_{\mathbf{a}}(\mu \mathrm{m})\end{array}$} & \multirow{2}{*}{$\begin{array}{l}\text { Average Surface } \\
\text { Roughness }(\mu \mathrm{m})\end{array}$} \\
\hline & & & $\mathbf{X}$ & $\mathbf{Y}$ & $\mathbf{Z}$ & & \\
\hline \multirow{5}{*}{1} & \multirow{5}{*}{180} & 3 & 10 & 18 & 16 & 2.331 & \multirow{5}{*}{1.859} \\
\hline & & 6 & 12 & 18 & 18 & 1.803 & \\
\hline & & 9 & 19 & 29 & 18 & 1.558 & \\
\hline & & 12 & 15 & 26 & 23 & 2.092 & \\
\hline & & 15 & 16 & 27 & 30 & 1.513 & \\
\hline \multirow{5}{*}{2} & \multirow{5}{*}{300} & 3 & 11 & 18 & 17 & 3.302 & \multirow{5}{*}{3.685} \\
\hline & & 6 & 13 & 22 & 20 & 3.522 & \\
\hline & & 9 & 9 & 16 & 21 & 3.35 & \\
\hline & & 12 & 11 & 25 & 24 & 3.596 & \\
\hline & & 15 & 12 & 18 & 16 & 4.657 & \\
\hline \multirow{5}{*}{3} & \multirow{5}{*}{530} & 3 & 8 & 13 & 12 & 4.258 & \multirow{5}{*}{4.019} \\
\hline & & 6 & 9 & 17 & 16 & 2.473 & \\
\hline & & 9 & 13 & 29 & 25 & 5.316 & \\
\hline & & 12 & 14 & 15 & 19 & 6.183 & \\
\hline & & 15 & 11 & 16 & 18 & 1.868 & \\
\hline
\end{tabular}

Table 7: Experimental Values for Non- Treated Tool Bit

\begin{tabular}{|c|c|c|c|c|c|c|c|}
\hline \multirow{2}{*}{ S. No } & \multirow{2}{*}{$\begin{array}{l}\text { Speed } \\
(\text { Rpm) }\end{array}$} & \multirow{2}{*}{$\begin{array}{l}\text { Time } \\
\text { (Min) }\end{array}$} & \multicolumn{3}{|c|}{ Cutting Forces (Kgf) } & \multirow{2}{*}{$\begin{array}{c}\text { Surface Roughness } \\
\left.\mathbf{R}_{\mathrm{a}}(\boldsymbol{\mu})\right)\end{array}$} & \multirow{2}{*}{$\begin{array}{l}\text { Average Surface } \\
\text { Roughness }(\mu \mathrm{m})\end{array}$} \\
\hline & & & $\mathbf{X}$ & $\mathbf{Y}$ & $\mathbf{Z}$ & & \\
\hline \multirow{5}{*}{1} & \multirow{5}{*}{180} & 3 & 20 & 29 & 11 & 2.537 & \multirow{5}{*}{4.219} \\
\hline & & 6 & 13 & 23 & 12 & 5.822 & \\
\hline & & 9 & 16 & 26 & 9 & 4.963 & \\
\hline & & 12 & 19 & 31 & 8 & 3.744 & \\
\hline & & 15 & 17 & 22 & 7 & 4.029 & \\
\hline \multirow{5}{*}{2} & \multirow{5}{*}{300} & 3 & 23 & 30 & 19 & 4.836 & \multirow{5}{*}{5.318} \\
\hline & & 6 & 28 & 42 & 27 & 5.415 & \\
\hline & & 9 & 32 & 40 & 28 & 6.023 & \\
\hline & & 12 & 29 & 44 & 28 & 5.728 & \\
\hline & & 15 & 33 & 43 & 33 & 4.586 & \\
\hline \multirow{5}{*}{3} & \multirow{5}{*}{530} & 3 & 13 & 29 & 18 & 5.029 & \multirow{5}{*}{5.780} \\
\hline & & 6 & 20 & 40 & 38 & 3.913 & \\
\hline & & 9 & 22 & 44 & 39 & 5.73 & \\
\hline & & 12 & 30 & 60 & 54 & 7.05 & \\
\hline & & 15 & 31 & 64 & 55 & 7.177 & \\
\hline
\end{tabular}

\subsubsection{Cutting Forces Variation}

The graphs have been plotted in between cutting forces Vs time for three different speeds as shown in figure 3, and also graphs between cutting forces Vs speed is plotted in figure 2. From the figures, we observed that lower the values of cutting forces in the case of a CT tool at a particular speed and time. This is because lesser tool wear and lesser distortions are observed at the intersection points of the tool bit and the work piece as mentioned by T.V. Sreerama Reddy et al. (2008)[28]. When we consider the cryogenically treated tool, it is observed that at $300 \mathrm{rpm}$ lower cutting forces are induced, this is because of the formation of build-up edge BUE resulting in decreased cutting forces and tool wear. To the knowledge of the author, the cutting forces are high at lower speeds of 180rpm and also at higher speeds of 540rpm, this is due to higher in 
frictional forces are generated at tool and work piece interface point.

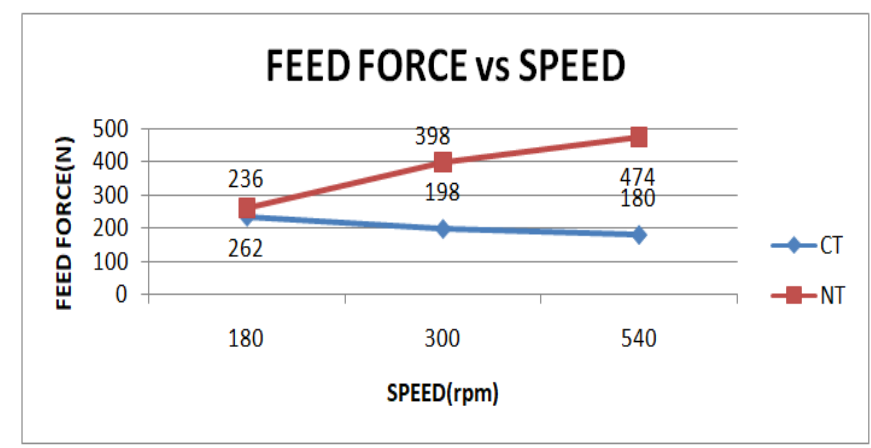

Figure 1: Variation of Cutting Force Vs Speed.
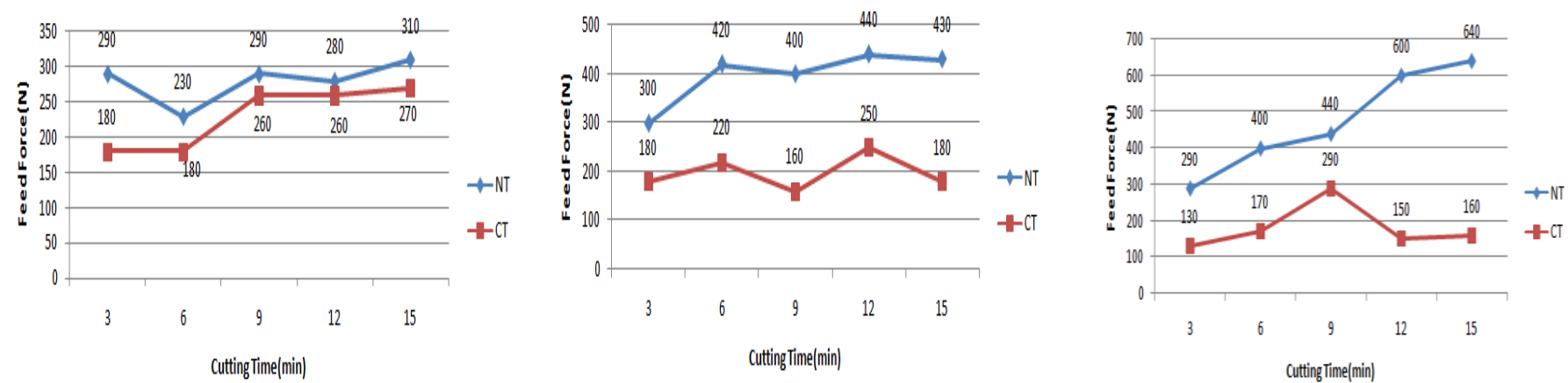

Feed Force Vs Time (Speed 180 Rpm) Feed Force Vs Time (Speed 300 Rpm) Feed Force Vs Time (Speed 540 Rpm) Figure 2: Cutting Force Vs Time for Different Speeds

\subsubsection{Power Variation}

The important factor to be considered on a tool with a single cutting edge is power consumption in turning operations. The study of power consumption determines tool life and obtains maximum productivity. The power required is calculated by using the following formula.

$$
\text { Power Required }=\frac{(F c * V c)}{60} * \frac{1}{\eta} \mathrm{W}
$$

Where, Fc - Main Cutting force in Newton

$$
\begin{aligned}
& \mathrm{V}_{\mathrm{c}} \text { - Cutting Speed }(\mathrm{m} / \mathrm{min}) \\
& \text { D- Efficiency of the machine. }
\end{aligned}
$$

Cutting Velocity is given by: $\mathrm{Vc}=\frac{\pi D N}{1000}(\mathrm{~m} / \mathrm{min})$.

Where, $\mathrm{D}=$ Diameter of the rod in $\mathrm{mm}$

$$
\mathrm{N}=\text { speed in } \mathrm{rpm}
$$

Figure 3 shows deviation of power with speed, showing increasing power consumption with increase in speed. Compared to the non-tread tool, the power consumption is less for CT tool. Here the reason is due to CT tool the grain structure is improved which will turn decreases the friction force at tool and work piece interface ponit. The cryogenically treated tool also reduces the forces during cutting and power consumption in the entire operation. 
Table 8: Power Calculations for Cryogenically Treated and Non-Treated Tool

\begin{tabular}{|c|c|c|c|c|c|c|c|c|c|}
\hline \multirow{2}{*}{$\begin{array}{l}\text { S. } \\
\text { No }\end{array}$} & \multirow{2}{*}{$\begin{array}{l}\text { Speed } \\
(\mathbf{R p m})\end{array}$} & \multirow{2}{*}{$\begin{array}{c}\text { Cutting Speed } \\
\text { V }_{c}(\mathbf{M} / \text { Min })\end{array}$} & \multirow{2}{*}{$\begin{array}{l}\text { Time } \\
\text { (Min) }\end{array}$} & \multicolumn{2}{|c|}{ Main Cutting Force $F_{c}(N)$} & \multicolumn{2}{|c|}{ Power $=\left(\mathrm{F}_{\mathrm{c}^{*}} \mathbf{V}_{\mathrm{c}}\right) / \mathbf{6 0} * \mathbf{D}$ (Watts) } & \multicolumn{2}{|c|}{$\begin{array}{l}\text { Total Power } \\
\text { (Watts) }\end{array}$} \\
\hline & & & & CT & NT & CT & NT & \multirow{6}{*}{37.64} & \multirow{6}{*}{41.6} \\
\hline \multirow{5}{*}{1} & \multirow{5}{*}{180} & \multirow{5}{*}{1.436} & 3 & 180 & 290 & 5.74 & 9.20 & & \\
\hline & & & 6 & 180 & 230 & 5.74 & 7.30 & & \\
\hline & & & 9 & 260 & 290 & 9.25 & 8.20 & & \\
\hline & & & 12 & 260 & 280 & 8.29 & 9.90 & & \\
\hline & & & 15 & 270 & 310 & 8.62 & 7.00 & & \\
\hline \multirow{5}{*}{2} & \multirow{5}{*}{300} & \multirow{5}{*}{2.394} & 3 & 180 & 300 & 9.58 & 15.60 & \multirow{5}{*}{52.67} & \multirow{5}{*}{105.42} \\
\hline & & & 6 & 220 & 420 & 11.70 & 22.34 & & \\
\hline & & & 9 & 160 & 400 & 8.51 & 21.28 & & \\
\hline & & & 12 & 250 & 440 & 13.3 & 23.40 & & \\
\hline & & & 15 & 180 & 430 & 9.58 & 22.88 & & \\
\hline \multirow{5}{*}{3} & \multirow{5}{*}{530} & \multirow{5}{*}{4.23} & 3 & 130 & 290 & 12.22 & 27.26 & \multirow{5}{*}{84.6} & \multirow{5}{*}{222.78} \\
\hline & & & 6 & 170 & 400 & 15.98 & 37.60 & & \\
\hline & & & 9 & 290 & 440 & 27.26 & 41.36 & & \\
\hline & & & 12 & 150 & 600 & 14.10 & 56.40 & & \\
\hline & & & 15 & 160 & 640 & 15.04 & 60.16 & & \\
\hline
\end{tabular}

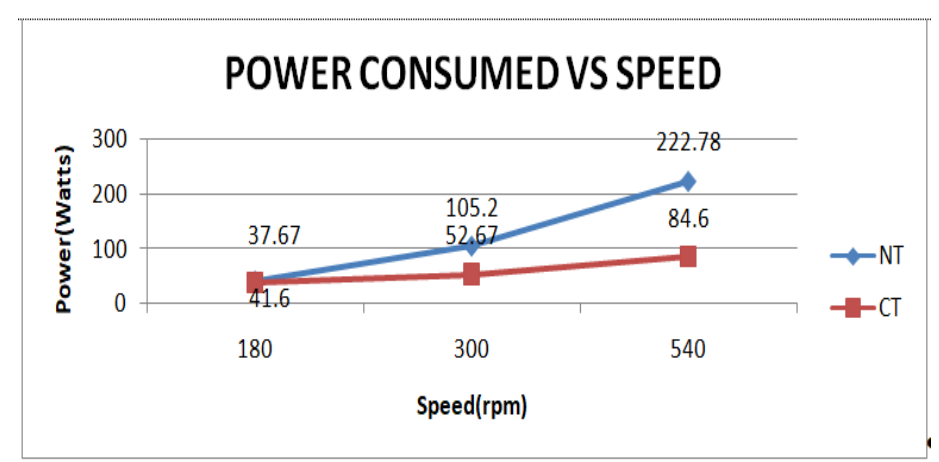

Figure 3: Variation of Total Power Vs Speed.

\subsubsection{Surface Roughness Variation}

Surface roughness is a major parameter in measuring the mach inability of the tool bit and it is very important parameters in observing the quality of machining (turning). In the above Figure 4 , the average of the surface roughness $\left(R_{a}\right)$ has been plotted w. $r . t$ the increasing speed in the above graph. The average surface roughness largely varies with increasing speed in case of a non-treated tool and it is on the higher side. This can be observed with an increase in slope. In the case of CT tool there is a slight variation in surface roughness value w. r. t speed and it is linear with the speed. There is a variation that can be seen between the cryogenically treated too and non-treated tools with a large gap between the two curves. The surface roughness in CT is always lesser than compared to the NT tool at any given speed. As suggested by T.V. Sreerama Reddy et al. (2008) [28], this may be in a cryogenically treated tool we observe the extremely fine grains in the material, which resulting in minor surface imperfections under the micro structural level thereby the surface finish will be improved. Soma Kumar et.al (1993) [24] stated that lesser vibrations are induced at lower cutting forces in machines. There by improving the surface finish. 


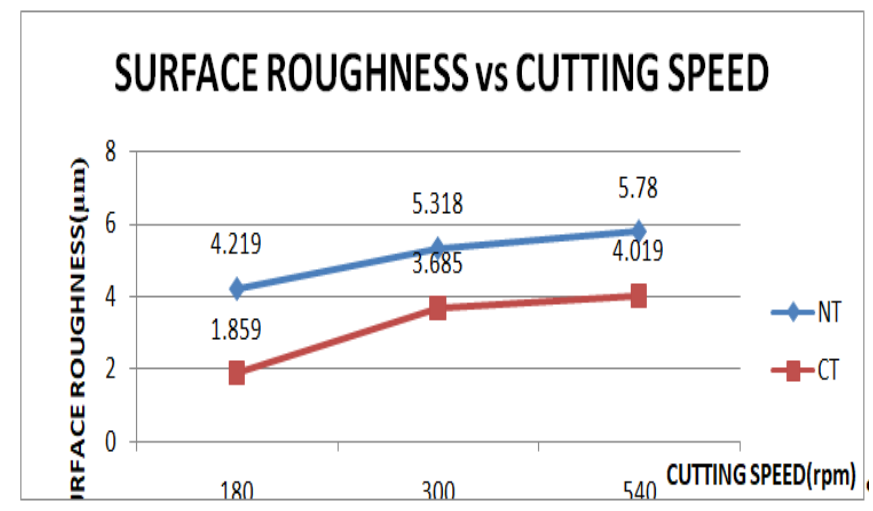

Figure 4: Surface Roughness Variation W. R. T Speeds.

\subsubsection{Flank Wear Variation}

The following graphs shown in Figure 6 indicate the flank wear variation in the tool w.r.t various speeds. The flank wear has been observed at regular time intervals in the tool till the nose fracture was seen. The flank wear is increased w.r.t time and this value is lesser in case of CT tool. Flank wear in CT tool is much lesser compared to the NT tool.

Figure 6 illustrate the tool bit life Vs speeds and we observed that tool life decreases with increasing speed in case of CT tool but the tool life is higher as compared to NCT tool. In table 9, the percentage improvement in tool bit life has been tabulated. The percentage improvement has been calculated by taking the tool life of non-treated tool as the reference. It can be seen that the CT tool life improves over non-treated tool. There is $20 \%$ improvement in the tool life at $180 \mathrm{rpm}$, $11 \%$ at 300rpm, and $14 \%$ at 530 rpm. T.V. Sreerama Reddy et al. (2008)[28], confirmed that due to CT, the tool generates more thermal conductivity because of a larger amount of heat dissipation which results in reduced tool abrasion which may reduce the effect of friction. Due to this flank wear was decreased and tool life has been increased. Barron (1982)[22] stated that, in CT the microstructure of the metal retains in the austenitic[16][17][18][19][20] state at room temperature because of this reason there is a drastic improvement in wear resistance. The carbide in the metal is evenly distributed all over the metal which improves wear properties.

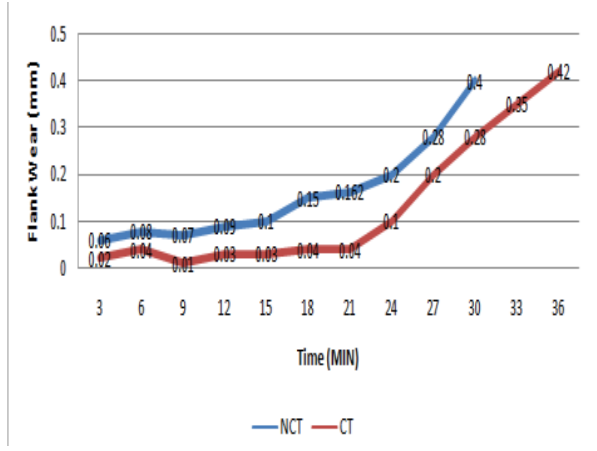

Tool Flank Wear Vs Time Till

Nose Fracture-180 Speed.

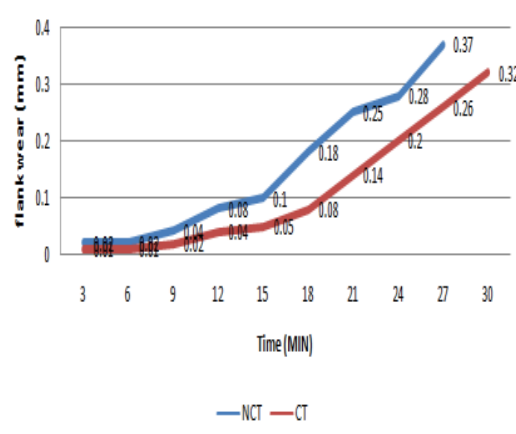

Tool Flank Wear Vs Time

Till Nose Fracture-300 Speed.

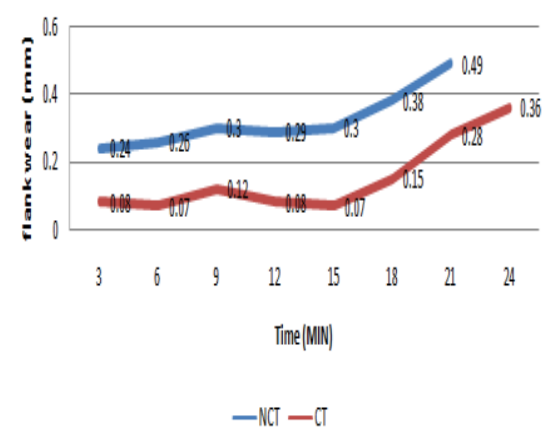

Tool Flank Wear Vs Time Till Nose Fracture-540 Speed.

Figure 5: Tool Flank Wear Vs Time for Different Speeds Up To Nose Fracture 


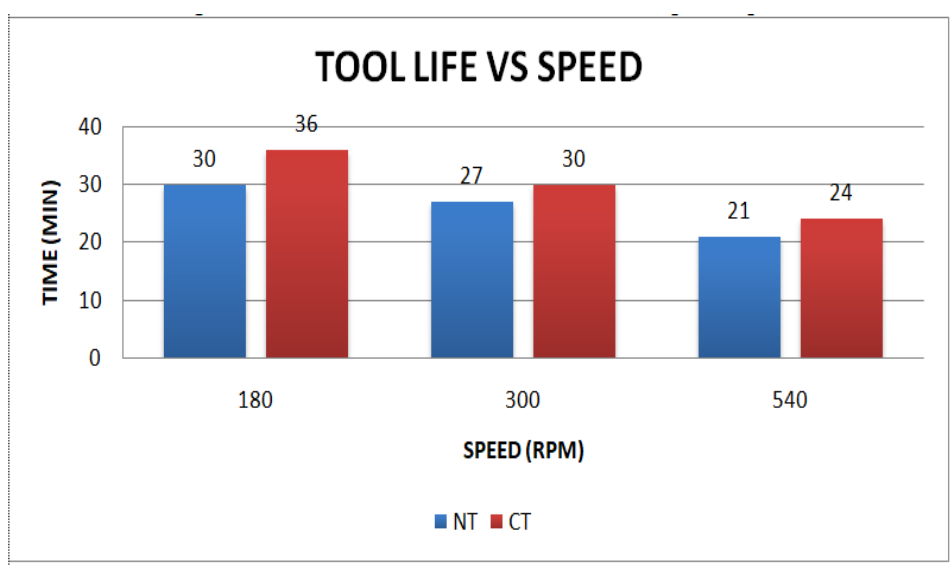

Figure 6: Tool Life Vs Speed for CT and NT Tool.

Table 9: Percentage of Improvement In Tool Bit Life of CT Tool

\begin{tabular}{|c|c|c|c|}
\hline \multirow{2}{*}{ Speed (Rpm) } & \multicolumn{2}{|c|}{ Tool Bit Life (Min) } & \multirow{2}{*}{ Percentage of Improvement } \\
\cline { 2 - 3 } & CT & NT & $20 \%$ \\
\hline 180 & 36 & 30 & $11 \%$ \\
\hline 300 & 30 & 27 & $14 \%$ \\
\hline 530 & 24 & 21 & \\
\hline
\end{tabular}

\subsection{Cutting Variables Effect on Surface RoughnessFlank Wear}

The L9 orthogonal array obtained by using MINITAB has been utilized for experimentation of the cryogenically treated tool to determine the influence of the turning variables on surface smoothness and flank wear. The table 10 below shows the iterations taken to carry out the experiment.

Table 10: Orthogonal Array Obtained for the Cutting Parameters of Three Levels

\begin{tabular}{|c|c|c|c|c|}
\hline $\mathbf{S}(\mathbf{R} \mathbf{p m})$ & $\mathbf{F}(\mathbf{M m} / \mathbf{R e v})$ & $\mathbf{D c}(\mathbf{M m})$ & Surface Roughness (Mm) & Flank Wear (Mm) \\
\hline 180 & 0.05 & 0.1 & 1.12 & 0.05 \\
\hline 180 & 0.1 & 0.2 & 1.45 & 0.06 \\
\hline 180 & 0.15 & 0.3 & 1.78 & 0.08 \\
\hline 300 & 0.05 & 0.2 & 1.21 & 0.07 \\
\hline 300 & 0.1 & 0.3 & 1.53 & 0.13 \\
\hline 300 & 0.15 & 0.1 & 1.86 & 0.1 \\
\hline 540 & 0.05 & 0.3 & 1.22 & 0.22 \\
\hline 540 & 0.1 & 0.1 & 1.61 & 0.25 \\
\hline 540 & 0.15 & 0.2 & 1.94 & 0.21 \\
\hline
\end{tabular}

\subsubsection{Surface Roughness Analysis}

The surface roughness $\left(\mathrm{R}_{\mathrm{a}}\right)$ of the experimental result was obtained by ANOVA of the general linear model for evaluating the parameters considerably influencing the surface roughness at $0.05(\alpha)$ significance level. Table 11 represents the P-values related to the F-test for each value of variation. The response significance is measured when p-value of the input is lesser than 0.05 . Table 11 above shows the factors feed and speed are significant on the average surface roughness since $\mathrm{P}<0.05$. Out of these, the feed has maximum influence on surface roughness $(\mathrm{F}=718.91)$ than other variabbbles which influence the surface roughness is the speed.

Figure 7 above shows the interaction plot between the output parameters of surface roughness and the input parameters. From the results it is seen that surface roughness increases w. r. $t$ an increasing feed. Figure 8 and 9 shows, the interaction plots. SudhansuRanjan Das et al. (2015)[25], states that feed rate influences the surface roughness integrity. R 
Suresh et al. (2012)[23] found that, higher feed rates increase thrust force and vibrations, which results in producing heat between a tool and the work piece. Due to this heat dissipation, the work piece will be plastically deformed resulting in higher surface roughness is achieved. SudhansuRanjan Das et al. (2015) [25], reported that during the turning operation, the surface finish will be enhanced for $170 \mathrm{~m} / \mathrm{min}$ cutting speed on cast iron-based alumina ceramic tools [12]. Below table 12, is the response table of means. Feed influences the most subsequently speed and depth of cut

Table 11: ANOVA for $R_{a}$

\begin{tabular}{|c|c|c|c|c|c|c|c|}
\hline Source & DF & Seq SS & Adj SS & Adj MS & $\mathbf{F}$ & $\mathbf{P}$ & Remarks \\
\hline speed & 2 & 0.02976 & 0.02976 & 0.01488 & 31.14 & 0.031 & Significant \\
\hline feed & 2 & 0.68696 & 0.68696 & 0.34348 & 718.91 & 0.001 & Significant \\
\hline DoC & 2 & 0.00096 & 0.00096 & 0.00048 & 1.00 & 0.500 & insignifican \\
\hline error & 2 & 0.00096 & 0.00096 & 0.00048 & & & \\
\hline Total & 8 & 0.71862 & & & & & \\
\hline
\end{tabular}
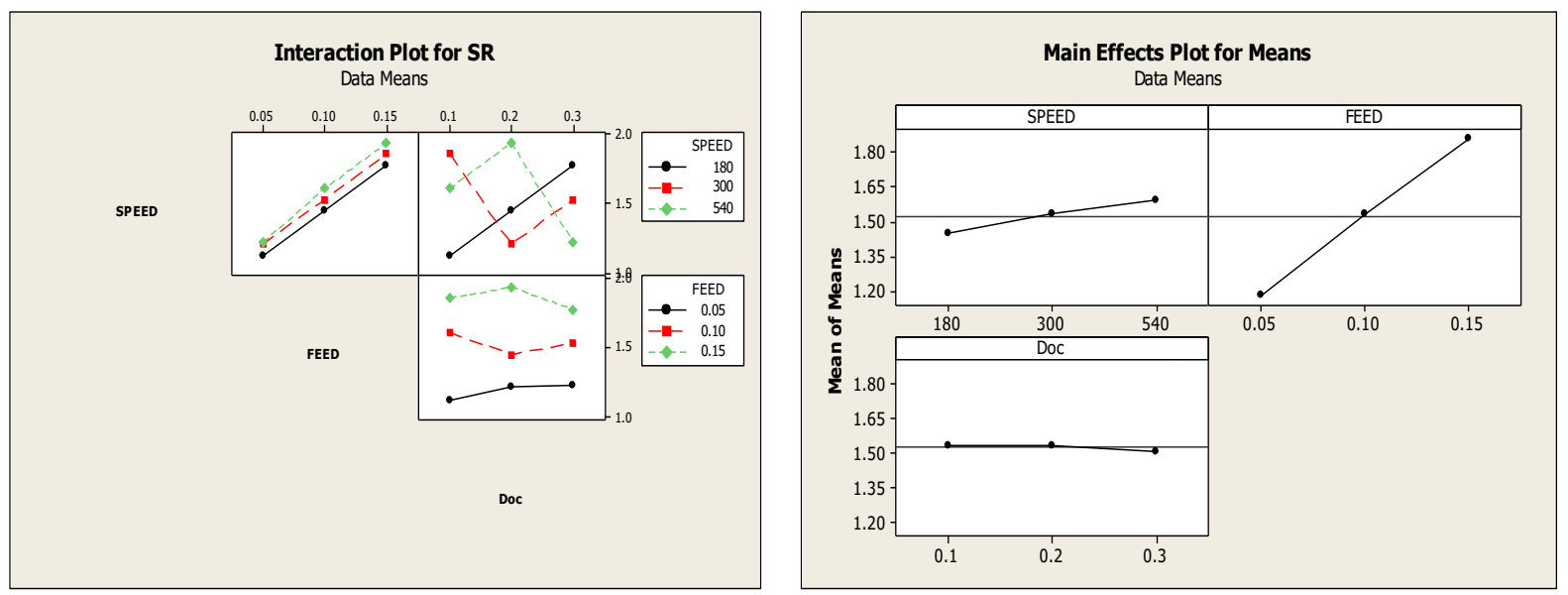

Figure 7: Interaction Plot For Surface Roughness.

Figure 8: Main Effects Graph For Ra.

Table 12: Response Table of Means for Surface Roughness.

\begin{tabular}{|c|c|c|c|}
\hline Level & Speed & Feed & Doc \\
\hline 1 & 1.45 & 1.183 & 1.530 \\
\hline 2 & 1.533 & 1.530 & 1.533 \\
\hline 3 & 1.590 & 1.860 & $\mathbf{1 . 5 1 0}$ \\
\hline delta & 0.140 & 0.677 & 0.023 \\
\hline rank & 2 & 1 & 3 \\
\hline
\end{tabular}

\subsubsection{Flank Wear Analysis}

Table 13 shows the parameters of the feed, speed, depth of cut and the type of tool were tested against the obtained flank wear and have been analyzed using ANOVA for their influence on the output parameter flank wear (mm) using the MINITAB software. The study was conducted at a $95 \%$ confidence level ( $\alpha=0.05$ significance level). Flank wear results are taken from ANOVA for turned, hardened steel in Table 13. Consider cutting speed as a principal element $(F=661)$ on flank wear response with the feed rate of $(F=25)$ related to cutting speed with a depth of cut $(F=21.00)$, these F-values are represented in F table with a $\mathrm{P}<0.05$ at $95 \%$ confidence. From the values, it is observed that flank wear did not depend on the DC but it depends on the depth of cut. When the depth of cut increases the flank was also increases slightly. 
Below figure shows the interaction plot for output parameter flank wear $v s$ input parameters. The flank wears increases with increasing speed. The interaction plots for flank wear are represented in Figures 9 and 10 Flank wears increases for higher $\mathrm{S}$ and DC. This consent with Suresh et al. (2012)[23], ststes that while increasing the cutting speed, the temperature of the contact tool also increases due to rubbing action between the tool and the work piece. due to this rubbing action, high friction is generated at tool-chip interface it may develop high pressures and temperatures at tooltip forming high thermal impact on a tool. This thermal impact leads to failing a tool as stated by SudhansuRajan Das et al.(2015)[25]. The strength at yield for the work piece material will decrease due to high cutting temperatures, which form low lesser flank wear $(<0.3 \mathrm{~mm})$ and tool forces. The lesser tool wear is attained by combining of low $\mathrm{S}$, and low DC at a medium F rate. In turning tool flank wear is caused by abrasion for given input variables as shown in figure11. This abrasive nature is due to some hard particles will present in the steelwork material. Speed influences flank wear the most followed by F and DC.

Table 13: ANOVA for Flank Wear

\begin{tabular}{|c|c|c|c|c|c|c|c|}
\hline Source & DF & Seq SS & Adj SS & Adj MS & F & P & Remark \\
\hline speed & 2 & $\begin{array}{c}0.044066 \\
7\end{array}$ & 0.0440667 & $\begin{array}{c}0.022033 \\
3\end{array}$ & 661.00 & 0.002 & Significant \\
\hline feed & 2 & $\begin{array}{c}0.001666 \\
7\end{array}$ & 0.0016667 & $\begin{array}{c}0.000833 \\
3\end{array}$ & 25.00 & 0.038 & Significant \\
\hline DoC & 2 & $\begin{array}{c}0.001400 \\
0\end{array}$ & 0.0014000 & $\begin{array}{c}0.000700 \\
0\end{array}$ & 21.00 & 0.045 & Significant \\
\hline Error & 2 & $\begin{array}{c}0.000066 \\
7\end{array}$ & 0.0000667 & $\begin{array}{c}0.000033 \\
3\end{array}$ & & & \\
\hline Total & $\mathbf{8}$ & $\begin{array}{c}\mathbf{0 . 0 4 7 2 0 0} \\
\mathbf{0}\end{array}$ & & & & & \\
\hline
\end{tabular}

$\mathrm{S}=0.00577350 \mathrm{R}-\mathrm{Sq}=99.86 \% \mathrm{R}-\mathrm{Sq}(\operatorname{adj})=99.44 \%$
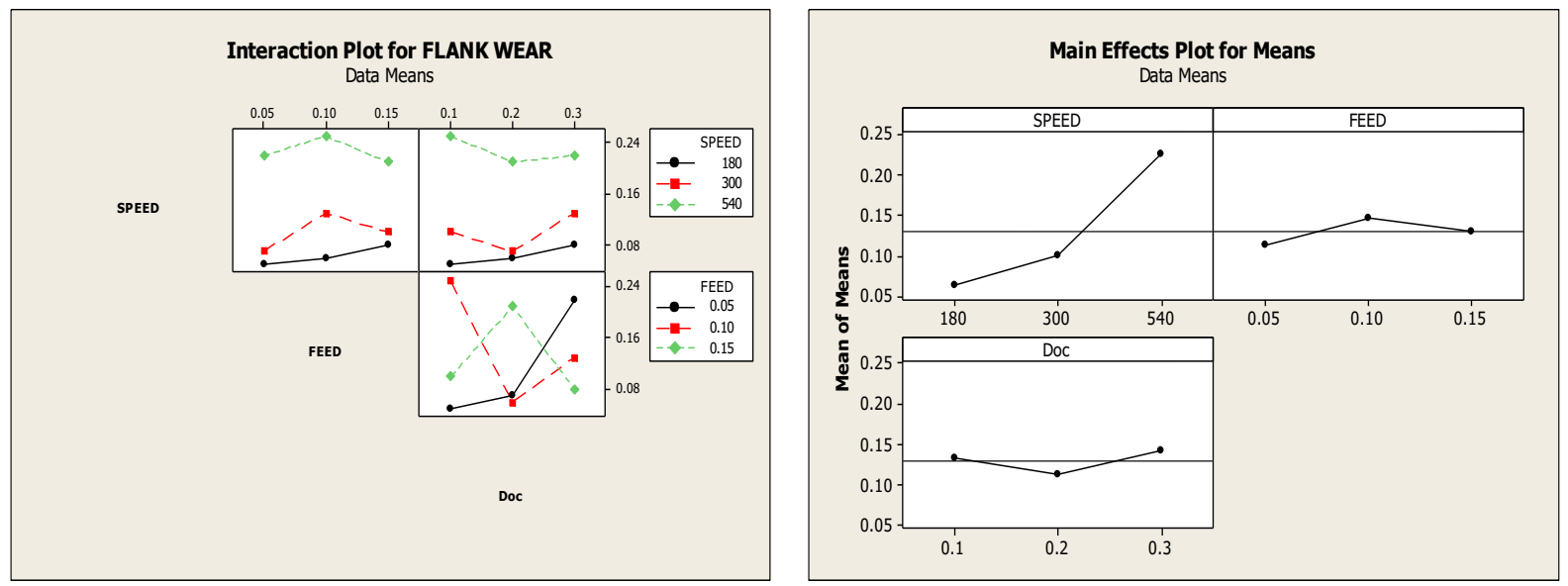

Figure 9: Interaction Plot For Flank Wear.

Figure 10: Main Effects Plot for Flank Wear.

Table 14: Response Table For Means For Flank Wear

\begin{tabular}{|c|c|c|c|}
\hline Level & S & F & DC \\
\hline 1 & 0.06333 & 0.11333 & 0.13333 \\
\hline 2 & 0.1 & 0.14667 & 0.11333 \\
\hline 3 & 0.22667 & 0.13 & 0.14333 \\
\hline Delta & 0.16333 & 0.03333 & 0.03000 \\
\hline Rank & 1 & 2 & 3 \\
\hline
\end{tabular}

\section{CONCLUSIONS}


The comparison test between the CT and NCT HSS tool, the cryogenically treated tool has a better performance over the non-treated tool. This is because; the cryogenically treated tool exhibited a better surface roughness than the non-treated tool for any given speed. The better surface finish is obtained because of finer grain size at the micro-level and also at lower cutting forces, low vibrations are produced.

Because of lesser in the amount of wear and the distortions near the edge of the cutting tool, there are lower cutting forces are observed in CT tool when it interacts with the work piece [9]. The decreased cutting forces may decrease the wear of the tool.

The total power consumed in the CT tool is always lower than the NCT tool because the power consumed is dependent on the tool bit cutting forces and these are also lower in the treated tool as a result the power also reduces correspondingly.

The variation of the flank wear w. r. $t$ time till the tool bit nose fracture indicates lower flank wear in case of CT HSS tool over the NCT tool. This improves the life of the CT tool. The improvement seen in the tool life is around $20 \%$ at $180 \mathrm{rpm}, 11 \%$ at 300rpm and $14 \%$ at 530rpm. This is because, the CT reduces the abrasion of the tool which reduces frictional force at tool chip interface and also enhances the thermal conductivity $(\mathrm{K})$ in tool. The enhanced $\mathrm{K}$ dissipates a large amount of heat lowering the wear of the flank in tool thereby improving tool life.

In the experimentation with the cryogenically treated tool by variation in the cutting parameter of S, F, and DC on a constant rod of the length of $120 \mathrm{~mm}$. surface roughness is primarily influenced by feed rate but it is least impacted by DC. Thow at higher velocities the BUE formation is limited it has a negative influence on the surface roughness. Therefore at higher cutting velocities the surface roughness increases.

From ANOVA and the interaction plots it can be determined that cutting velocity primarily influences flank wear. Although, the depth of cut is doesn't highly influence the flank wear.

The optimal turning variables obtained by Taguchi [5] analysis, we have $\mathrm{S}=180 \mathrm{rpm}, \mathrm{F}=0.05 \mathrm{~mm} / \mathrm{rev}$ and $\mathrm{DC}=0.3 \mathrm{~mm}$ for surface roughness. For flank wear the optimized values obtained are $\mathrm{S}=180 \mathrm{rpm}, \mathrm{F}=0.05 \mathrm{~mm} / \mathrm{rev}, \mathrm{DC}=0.2 \mathrm{~mm}$. The overall paper explains how the cryogenically treated HSS tool is better than the NCT HSS tool.The effect of the turning variables on flank wear and $\mathrm{R}_{\mathrm{a}}$ has also been found out as a part of the project thereby obtaining the optimized parameters for the given speeds.

\section{REFERENCES}

1. A.D. Shirbhate, N.V. Deshpande, A.K. Pitale and C.R. Patil (2012) "Performance evaluation of cryogenically treated M2 grade HSS tools in various machining operations".

2. Ahmed M, Ahmed F Ismail, Y.A Abakr and A.K.M Nurul Amin (2007)." Effectiveness of cryogenic machining with modified tool holder." Journal of Materials Processing Technology, Vol. 185, 9196.

3. Amrita Priyadarshini and K.P Maity (2007) "A Study of the Effect of Cryogenic Treatment on the Performance of High Speed Steel Tools and Carbide Inserts" International Journal of Engineering Trends and Technology, Vol. 7, 278288.

4. A. Shokranil, V. Dhokial, P. Muñoz-Escalona and S.T. Newman (2013) "State-of-the-art cryogenic machining and processing". International Journal of Computer Integrated Manufacturing, Vol. 26,616-625. ISSN 0951-192X.

5. A.V.N.L. Sharma, K.Venkatasubbaiah and P.S.N. Raju (2013): 'Parametric Analysis and Multi Objective Optimisation of 
Cutting Parameters in Turning Operation of EN353-With CVD Cutting Tool Using Taguchi Method', International Journal of Engineering and Innovative Technology, Vol. 2, No. 9, 283-289, ISSN 22773754.

6. A.V.N.L. Sharma, K.Venkatasubbaiah, and V. Diwakar Reddy (2013), 'Influence of Cutting Parameters on surface roughness Metal removal rate and power consumption on EN353 with Coated Tools by ANOVA', Central Manufacturing Technology Institute, Manufacturing Technology Today, Vol. 12, No. 3, 10-23, ISSN 09727396.

7. Benfredj, N., Sidhom, H. and Braham, C. (2006), "Ground surface improvement of the austenitic stainless steel AISI 304 using cryogenic cooling. " Surface and Coatings Technology, Vol. 200, 48464860.

8. D.Candane, N.Alagumurthi and K.Palaniradja (2013) "Effect of Cryogenic treatment on micro structure and wear characteristics of AISI M35 HSS. International Journal of Materials Science and Applications.

9. E. Aslan, N. Camuscu and B. Bingoren (2007) "Design optimization of cutting parameters when turning hardened AISI 4140 (63 HRC) with Al2O3+TiCN mixed ceramic tool, Materials \& Design, Vol.28, 16181622.

10. F. Cajner, V. Leskovšek, D. Landek, and H. Cajner,(2008) "The effect of Deep-Cryogenic treatment on high speed steel properties", Materials and Manufacturing Processes, Vol.24,743746.

11. Gu k, wang $J$ and Zhou y (2014)'Effect of cryogenic treatment on wear resistance of Ti-6Al-4V alloy for biomedical applications. ”Journal of the Mechanical Behaviour of Biomedical Materials, Vol. 30, 131139.

12. H. Aouici, M. A. Yallese, B. Fnides, K. Chaoui and T. Mabrouki (2011), Modeling and "Optimization Of Hard Turning Of X38crmov5-1 Steel With CBN Tool: Machining Parameters Effects On Flank Wear And Surface Roughness, " JMST, Vol.25, 28432851 .

13. Lakhwinder Pal Singh, Jagtar Singh (2011) "Effects of Cryogenic Treatment on High-speed Steel Tools". Journal of Engineering and Technology, Vol. 1, 8893.

14. Molinari, Pellizzari, Gialanella, Straffelini and Stiasny (2001) "Effect of Deep Cryogenic Treatment on the Mechanical Properties of Tool Steels”. Journal of Materials Processing Technology, Vol.118, 350355.

15. M. Kaladhar, K. Venkata Subbaiah, Ch. Srinivasarao and K.Narayana Rao (2010): Optimization of Process Parameters in turning of AISI 202 Austenitic Stainless Steel, ARPN Journal of Engineering and applied sciences, Vol.5, No.9, 79-87. (ISSN: 18196608).

16. M. Kaladhar, K. Venkata Subbaiah and Ch. Srinivasarao (2011)"Performance evaluation of coating materials and process parameters optimization for surface quality during turning of AISI 304 austenitic stainless steel”, International Journal of Engineering, Science and Technology, Vol. 3, No. 4, 89-102. (ISSN: 22789510).

17. M.Kaladhar, K Venkata Subbaiah and Ch. Srinivasa Rao (2012): "Parametric optimization during machining of AISI 304 austenitic stainless steel using CVD coated Duratomic ${ }^{T M}$ cutting insert", International Journal of Industrial Engineering Computations, Vol.3, 577-586.

18. M. Kaladhar, K. Venkata Subbaiah and Ch. Srinivasarao (2012): Determination of Optimum Process Parameters during turningof AISI 304 Austenitic Stainless Steels using Taguchi method and ANOVA,International Journal of Lean Thinking,Vol.3(1),119.

19. [19] M.Kaladhar, K Venkata Subbaiah and Ch. Srinivasa Rao, K Narayana Rao (2012): Process parameters optimization and coatings influence on the surface quality during turning of AISI 202 austenitic stainless steel, International Journal of Machining and Machinability of Materials, Vol. 11, and Issue 4, 371383.

20. M. Kaladhar, K. Venkata Subbaiah and Ch. Srinivasa Rao (2013): Optimization of surface roughness and tool flank wear in 
turning of AISI 304 austenitic stainless steel with CVD coated tool, Journal of Engineering Science and Technology, Vol. 8, Issue 2, 165-176.

21. Paul S, Dhar NR and Chattopadhyay A.B (2001) "Beneficial effects of cryogenic cooling over dry and wet machining on tool wear and surface finish in turning AISI 1060 steel. " Journal of Materials Processing Technology, Vol. 116, 4448.

22. R. F. Barron (1982) “Cryogenic Treatment Of Metals To Improve Wear Resistance, Cryogenics” Cryogenics, 409413.

23. R. Suresh, S. Basavarajappa, V. N. Gaitonde and G. L. Samuel(2012), "Machinability investigations on hardened AISI 4340 steel using coated carbide insert, International Journal of Refractory Metals and Hard Materials, "Vol.33, 7586.

24. Sornakumar T, Krishnamurthy R, Gokularathnam CV (1993). "Machining performance of phase transformation toughened alumina and partially stabilised zirconia composite cutting tools.” Journal of European Ceramic Society, Vol. 12, 455460.

25. SudhansuRanjan Das, DebabrataDhupal and Amaresh Kumar (2015) "Study of surface roughness and flank wear in hard turning of AISI 4140 steel with coated ceramic inserts". Journal of Mechanical Science and Technology, Vol. 29, 43294340.

26. Sunil Magadum, Arun Kumar, Yognath VG and Srinivas CK (2014) "Effect of Cryogenic cooling in turning SS304 using coated carbide at high cutting speeds”. All India Manufacturing Technology, Design and Research Conference.

27. SutkiAkincioglu. Hassan Gokkaya and Ilyas Uygur (2014) “A Review of Cryogenic Treatment on Cutting Tools” International Journal of Advanced Manufacturing Technology, Vol.78, 16091627.

28. T.V.Sreerama Reddy, T.Sornakumar, M.Venkatarama Reddy and R.Venkatram (2009) "Machinability of C45 steel with deep cryogenic treated tungsten carbide cutting tool inserts", International Journal of Refractory Metals and Hard Materials, Vol. $27,181185$.

29. Taur, P. G., and S. A. Sonawane. "ANALYSIS OF WEAR RESISTANCE OF TOOL STEEL AFTER DEEP CRYOGENIC TREATMENT." International Journal of Mechanical and Production Engineering Research and Development (IJMPERD) 5.1 (2015):1124.

30. BISWAL, CHINMAYA, RAHULJI DALA, and KIRAN KULKARNI. "EXECUTION OF CRYOGENICALLY TREATED BRISK STEEL ENTERS IN EXHAUSTING OF AUSTENITIC SOLIDIFIED STEELS." International Journal of Mechanical and Production Engineering Research and Development (IJMPERD) 9.5 (2019):35-42.

31. ABBASZADEH, BEHZAD, and AMIR GHAFOURI. "INVESTIGATION OF TOOL LIFE IN ALSIC COMPOSITE MATERIAL WITH ULTRASONIC WAVES MACHINING." International Journal of Mechanical and Production Engineering Research and Development (IJMPERD) 8.3 (2018):499506.

32. JHA, BISHNU M., and A. MANDAL. "NEURAL NETWORK BASED MODELS FOR SURFACE ROUGHNESS OBTAINED DURING ELECTROCHEMICAL MACHINING OF SG IRON." International Journal of Mechanical Engineering (IJME) 5.5 (2016):718.

33. Shather, Saad Kariem. "ENHANCEMENT OF SURFACE ROUGHNESS AND METAL REMOVAL RATE BY USING COMBINED ABRASIVES DURING MAGNETIC ABRASIVE FINISHING." IMPACT: International Journal of Research in Engineering \& Technology 7.8 (2019):1-8.

\section{AUTHOR'S PROFILE}



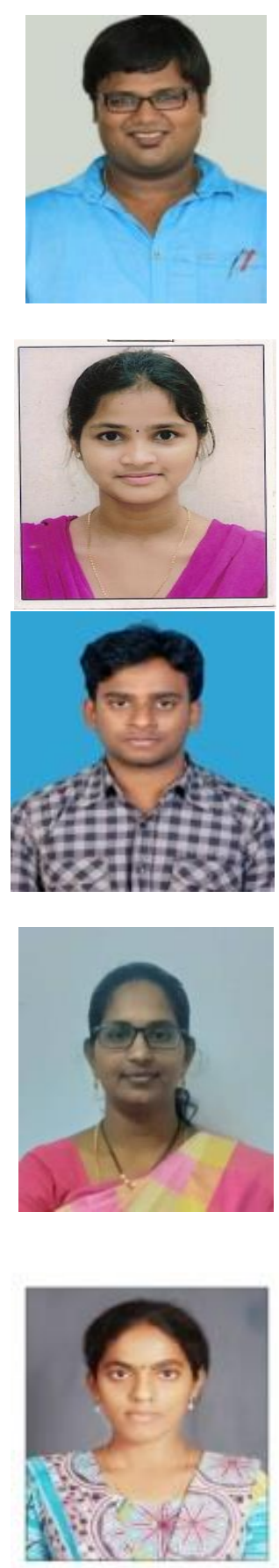

Mr.S.V.Satya Prasad, received his B.Tech in mechanical engineering from JNTU Kakinada and M.Tech in Industrial engineering from Andhra university. He is currently Asst. Professor in the department of mechanical engineering in VIEW, Visakhapatnam, Andhra Pradesh, India. He has an experience of 09 years as an academician. He is also a research scholar from NIT Jamshedpur. His area of expertise in material science. He has authored many research articles and conference papers for many repeated journals.

Mrs. P.Prasanna Kumari, received her bachelor degree in mechanical engineering and master degree in machine design from JNT University, Kakinada. Present she is working as Asst. Prof. in the department of mechanical engineering, VIEW, Visakhapatnam, AndhraPradesh, India. She has an experience of 2 years as an academician. Her area of specialization is dealing with acoustics and machine design.

A.V.Pradeep, received his B.Eng M.Eng in mechanical engineering from JNTU Kakinada. He is currentlyAsst. Professor in the department of mechanical engineering in VIEW, Visakhapatnam, AndhraPradesh, India. He has an experience of 8 years as academician. He is also a reesrch scholar from JNTUK. His area of expertise in manufacturing and metal cutting. He has authored many research articles and conference papers for many repeated journals.

P.Kiranmayi, M.Tech(Industrial Engineering) has 3 years of teaching experience in mechanical engineering. Her research focuses on optimization techniques for solving complex engineering problems, statistical quality control and engineering materials. Currently she is working as an Assistant Professor in Mechanical Engineering department in Gayatri Vidya Parishad College for Degree and PG Courses (A).

Mrs. K.Vahini, received her bachelor degree in mechanical engineering from JNT University, Kakinada and master degree in marine engineering from IMU, Visakhapatnam. Present she is working as Asst. Prof. in the department of mechanical engineering, VIEW, Visakhapatnam, Andhra Pradesh, India. She has an experience of 7 years as an academician. She is also a research scholar from Andhra University, working on alternative fuels to diesel engines. Her area of specialization is dealing with I.C engines and machine design. 